\title{
Hypothermia modulates myeloid cell polarization in neonatal hypoxic-ischemic brain injury
}

Marina Seitz ${ }^{1,2}$, Christian Köster ${ }^{1,2}$, Mark Dzietko ${ }^{1,2}$, Hemmen Sabir ${ }^{3,4}$, Meray Serdar $^{1,2}$, Ursula Felderhoff-Müser ${ }^{1,2}$, Ivo Bendix ${ }^{1,2^{*}+}$ and Josephine Herz ${ }^{1,2^{*}}$ (D)

\begin{abstract}
Background: Neonatal encephalopathy due to hypoxia-ischemia $(\mathrm{HI})$ is a leading cause of death and disability in term newborns. Therapeutic hypothermia (HT) is the only recommended therapy. However, $30 \%$ still suffer from neurological deficits. Inflammation is a major hallmark of HI pathophysiology with myeloid cells being key players, participating either in progression or in resolution of injury-induced inflammation. In the present study, we investigated the impact of HT on the temporal and spatial dynamics of microglia/macrophage polarization after neonatal $\mathrm{HI}$ in newborn mice.
\end{abstract}

Methods: Nine-day-old C57BL/6 mice were exposed to HI through occlusion of the right common carotid artery followed by $1 \mathrm{~h}$ hypoxia. Immediately after $\mathrm{HI}$, animals were cooled for $4 \mathrm{~h}$ or kept at physiological body core temperature. Analyses were performed at 1, 3 and 7 days post HI. Brain injury, neuronal cell loss, apoptosis and microglia activation were assessed by immunohistochemistry. A broad set of typical genes associated with classical (M1) and alternative (M2) myeloid cell activation was analyzed by real time PCR in ex vivo isolated CD1 1 b+ microglia/macrophages. Purity and composition of isolated cells was determined by flow cytometry.

Results: Immediate HT significantly reduced HI-induced brain injury and neuronal loss 7 days post HI, whereas only mild non-significant protection from $\mathrm{HI}$-induced apoptosis and neuronal loss were observed 1 and 3 days after HI. Microglia activation, i.e., Iba-1 immunoreactivity peaked 3 days after $\mathrm{HI}$ and was not modulated by HT. However, ex vivo isolated $\mathrm{CD} 11 \mathrm{~b}^{+}$cells revealed a strong upregulation of the majority of $\mathrm{M} 1$ but also M2 marker genes at day 1 , which was significantly reduced by $\mathrm{HT}$ and rapidly declined at day 3 . HI induced a significant increase in the frequency of peripheral macrophages in sorted $C D 11 b^{+}$cells at day 1, which deteriorated until day 7 and was signifcantly decreased by HT.

Conclusion: Our data demonstrate that HT-induced neuroprotection is preceded by acute suppression of HIinduced upregulation of inflammatory genes in myeloid cells and decreased infiltration of peripheral macrophages, both representing potential important effector mechanisms of HT.

\footnotetext{
*Correspondence: ivo.bendix@uk-essen.de; josephine.herz@uk-essen.de

${ }^{\dagger}$ Ivo Bendix and Josephine Herz contributed equally to this work

${ }^{1}$ Department of Pediatrics I, Neonatology \& Experimental Perinatal

Neurosciences, University Hospital Essen, University Duisburg-Essen,

Hufelandstr. 55, 45147 Essen, Germany

Full list of author information is available at the end of the article
}

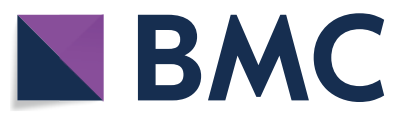

Aurcens This article is licensed under a Creative Commons Attribution 4.0 International License, which permits use, sharing, adaptation, distribution and reproduction in any medium or format, as long as you give appropriate credit to the original author(s) and the source, provide a link to the Creative Commons licence, and indicate if changes were made. The images or other third party material in this article are included in the article's Creative Commons licence, unless indicated otherwise in a credit line to the material. If material is not included in the article's Creative Commons licence and your intended use is not permitted by statutory regulation or exceeds the permitted use, you will need to obtain permission directly from the copyright holder. To view a copy of this licence, visit http://creativecommons.org/licenses/by/4.0/. The Creative Commons Public Domain Dedication waiver (http://creativeco mmons.org/publicdomain/zero/1.0/) applies to the data made available in this article, unless otherwise stated in a credit line to the data. 
Keywords: Microglia, Macrophages, Neonatal hypoxia-ischemia, Hypothermia, Myeloid cell polarization, M1 M2 polarization

\section{Introduction}

Neonatal hypoxic-ischemic (HI) brain injury is a leading cause of childhood mortality and neurodevelopmental morbidity [1]. Affecting 1-6 per 1000 newborns in Western societies with a mortality of up to $30 \%$, it represents an enormous individual and familial burden with high socioeconomic costs. Frequent consequences are cerebral palsy, epilepsy, auditory and visual impairment as well as cognitive and motor deficits in later life $[1,2]$. To date, therapeutic hypothermia (HT) is the standard therapy (ILCOR guidelines 2015). However, $30 \%$ of cooled infants still suffer from major neurological problems [3], because of a short therapeutic window (first $6 \mathrm{~h}$ of life), limited efficacy in more severe cases and a high number needed to treat [4]. This is supported by our previous experimental findings that protection of secondary injury processes and long-term cognitive deficits is limited by acute HT [5]. In spite of tremendous efforts to identify new and/ or additional treatment strategies, translation into clinical practice is still challenging. Experimental and clinical studies showed that anti-apoptotic and anti-excitatory agents, such as insulin-like growth factor-1, the noble gas xenon and dizocilpine failed to provide greater protection than HT alone [6-8]. In support of this, we have previously shown in a murine model of $\mathrm{HI}$-induced brain injury that potential interactions with regenerative stem cell therapies may occur due to alteration of the brain tissue environment following HT [9]. These studies demonstrate that a better knowledge of hypothermia's effector mechanisms is needed to guide the rational design of combination treatments.

Inflammation is a major hallmark of $\mathrm{HI}$ pathophysiology, with myeloid cells playing a key role, participating in progression or resolution of injury-induced inflammation. Functional differences in myeloid cells are traditionally ascribed to coexisting diverse phenotypes with classically activated pro-inflammatory M1 cells and alternatively activated anti-inflammatory M2 cells. While M1 cells are supposed to contribute to neurodegeneration, M2 cells are suggested to promote repair and regeneration [10]. In addition to these cell types further immunoregulatory phenotypes have been described [11]. We and others have experimentally shown that $\mathrm{HI}$ induces pronounced differences in the expression of typical M1 and M2 markers in the injured brain [12, 13]. However, analyses were mainly performed in total tissue lysates, which is limited, since typical M1 and M2-related molecules, such as pro- and anti-inflammatory cytokines, are not exclusively expressed by myeloid cells. Furthermore, despite of the elegant possibility to perform selective analysis on ex vivo sorted $\mathrm{CD}_{11} \mathrm{~b}^{+}$myeloid cells from injured brains in different perinatal brain injury models, including traumatic brain injury, peripheral inflammation, HI and perinatal stroke [14-17], the composition of sorted cells with regard to their origin, i.e., peripheral monocytes/macrophages vs. resident microglia, remained largely unknown.

Even though anti-inflammatory effects of HT and inhibition of microglia activation have been proven in different models of HI-induced brain injury $[9,18]$, its impact on myeloid cell polarization is unknown. In an adult ischemic brain injury model, it was previously shown that pharmacologically induced hypothermia reduces mRNA expression of typical M1 markers, such as IL-23, IL-12 and iNOS, while M2 marker expression, e.g., Fizz-1, Ym-1 and Arg-1 were increased [19]. In one of our recent studies, we also observed a significant reduction of the pro-inflammatory M1 markers IL-6 and TNF-alpha following HT after neonatal HI [9]. Nevertheless, in both studies, total brain lysates were analyzed at a single timepoint, impeding clear cut conclusions about the timedependent modulation of myeloid cells after HT.

In the present study, we investigated the effect of HT on the temporal and spatial dynamics of microglia/macrophage cell polarization 1, 3 and 7 days after neonatal $\mathrm{HI}$ via immunohistochemistry and gene expression analyses in ex vivo isolated CD11 $\mathrm{b}^{+}$myeloid cells. Flow cytometry analyses were used to get further insight, to which extent peripheral myeloid cells and resident microglia contributed to alterations observed in the total $\mathrm{CD} 11 \mathrm{~b}^{+}$cell population isolated from HI-injured brains.

\section{Methods}

\section{Animal care and group allocation}

Experiments were performed in accordance with the ARRIVE guidelines with government approval by the State Agency for Nature, Environment and Consumer Protection North Rhine-Westphalia. C57BL/6 J mice, initially ordered from Charles River were bred in house and kept under a $12 \mathrm{~h}$ light/dark cycle with food and water ad libitum. Bodyweight was recorded at postnatal day 9 (P9), P10, P11 and P16. A total of 157 animals (81 female, 76 male) derived from 19 litters were enrolled. Thirtythree mice ( 16 female, 17 male) underwent sham surgery. Out of the remaining 124 exposed to hypoxia-ischemia 7 animals (5.7\%, 2 female, 5 male) died during hypoxia. 
No mortality was observed afterwards until sacrifice of animals 1, 3 and 7 days after HI. For all analyses, animals per litter and experiment were randomly assigned to 3 experimental groups (sham, $\mathrm{HI}+$ normothermia (NT), $\mathrm{HI}+\mathrm{HT}$ ) prior to intervention. For immunohistochemistry, pups of one litter were further randomly divided to two timepoints of analyses prior to experimentation. Due to small litter size of mice and required pooling of samples for cell sorting, animals of one litter with 3 experimental groups (sham, NT, HT) could not be further divided into different timepoints of analysis. To control the potential influence of weight and sex, a stratified randomization was performed followed by simple randomization within each block to assign pups to individual groups. Individuals involved in data analysis knew the animals' designation but were blinded to group assignment. The first set of mice (31 female, 26 male) was used for histology and immunohistochemistry analysis. The second set of animals ( 47 female, 43 male) was used for magnetic activated cell sorting, followed by flow cytometry and mRNA expression analyses. Additional 3 (1 female, 2 male) mice were used for immune cell isolation and immediate flow cytometry analysis.

\section{Neonatal hypoxia-ischemia and therapeutic hypothermia} Hypoxic-ischemic brain injury was induced in 9-dayold animals as previously described [5, 9, 20, 21]. Briefly, the right common carotid artery was occluded through cauterization (high temperature cauter, $1200{ }^{\circ} \mathrm{C}$, Bovie, USA) under isoflurane anesthesia (1.5-2.5 Vol\%) followed by $1 \mathrm{~h}$ hypoxia $\left(10 \% \mathrm{O}_{2}\right)$ in an air-tight oxygen chamber (OxyCycler, Biospherix, USA) after $1 \mathrm{~h}$ recovery with their dams. According to our previous study, where we identified a physiological body core (i.e., nesting) temperature of $35{ }^{\circ} \mathrm{C}$ for P9 mice [5] animals were placed on a warming mat (Harvard Apparatus, USA) to maintain nesting temperature during hypoxia. Shamoperated animals received anesthesia and neck incision only. Perioperative analgesia was ensured by subcutaneous administration of $0.1 \mathrm{mg} / \mathrm{kg}$ buprenorphine. Based on our previous reports [5, 9], HT was applied immediately following $\mathrm{HI}$ for $4 \mathrm{~h}$ with a target temperature of $T_{\text {rectal }} 32{ }^{\circ} \mathrm{C}$. Mice were placed on a custom-made plate with temperature control by water circulation. Controls (NT) were placed on a warming mat to maintain physiological body core temperature $\left(T_{\text {rectal }} 35^{\circ} \mathrm{C}\right)$ conforming to our previous work $[5,9]$.

\section{Tissue processing, histology and immunohistochemistry}

1,3 or 7 days after HI, mice were deeply anesthetized by intraperitoneal (i.p.) injections of chloralhydrate and transcardially perfused with ice-cold PBS followed by perfusion with 4\% PFA. Brains were removed, post-fixed in 4\% PFA overnight followed by dehydration in 30\% Sucrose for $24 \mathrm{~h}$. Brains were snap frozen in isopentane on dry ice. Tissue injury was assessed and scored on cresyl violet stained $20 \mu \mathrm{m}$ cryostat sections as previously described $[5,9,20,22]$ with minor modifications. Briefly, 9 regions were scored: the anterior, middle and posterior cortex, CA1, CA2, CA3 and dentate gyrus of the hippocampus, the striatum and the thalamus. Each region was given a rating from 0 to 3 ( 0 -no detectable cell loss or $0 \%$ infarct area (1 day after $\mathrm{HI}), 1-$ small focal areas of neuronal cell loss, ventricle enlargement at the striatal level or $10-40 \%$ infarct area (1 day after $\mathrm{HI}$ ), 2columnar damage in the cortex or moderate to severe cell loss in the other regions or $40-60 \%$ infarct area ( 1 day after HI), 3-cystic infarction and gliosis or $60-100 \%$ infarct area (1 day after $\mathrm{HI}))$. The sum score from different regions was calculated for each animal resulting in a total maximum score of 27. Tissue atrophy was determined by measurement of tissue areas in ipsi- and contra-lateral hemispheres at a distance of $400 \mu \mathrm{m}$ using Image J software (NIH, USA). Tissue loss was determined by comparison with contralateral volumes according to the following equation: 1 -(volume ratio (left vs. right) $) \times 100$.

For evaluation of cellular degeneration, neuronal loss, microglia activation and polarization, $20 \mu \mathrm{m}$ cryostat sections taken at the hippocampal level $(-1.9$ to $-2.0 \mathrm{~mm}$ from bregma) were stained according to our previous reports $[5,9,21]$. Briefly, tissue sections were thawed at $37^{\circ} \mathrm{C}$ for $15 \mathrm{~min}$ and incubated with $1 \% \mathrm{BSA}, 0.3 \%$ cold fish skin gelatin (Sigma Aldrich, Germany) in 1\% Tween 20 in Tris-buffered saline (TBS-T) for $1 \mathrm{~h}$ at room temperature followed by primary antibody incubation at $4{ }^{\circ} \mathrm{C}$ over night. The following primary antibodies were used: rat anti-mouse NeuN (1:100, Millipore), rabbit antimouse/rat Iba-1 (1:1000, Wako), rat anti-mouse CD86 (1:200, abcam), goat anti-mouse CD206 (1:100, R\&D Systems). Antibody binding was visualized by incubation with appropriate Alexa Flour 488 or Alexa Flour 555 conjugated secondary antibodies (anti-rat/goat/rabbit, all 1:500, all Thermo Scientific) for $2 \mathrm{~h}$ at room temperature. Nuclei were counterstained with 4',6-Diamidin-2-phenylindol (DAPI, 100 ng/ml; Molecular Probes, USA). Cellular degeneration was determined by staining of DNA fragmentation using terminal transferase dUTP nick end labeling (TUNEL) according to the manufactures' protocol (In situ Cell Death Detection Kit, Roche, Switzerland).

\section{Quantification of cellular degeneration, neuronal loss, microglia activation and polarization}

Cellular degeneration and neuronal loss were quantified in TUNEL and NeuN-stained tissue sections via fluorescence microscopy according to our previous protocols $[5$, 
9, 21]. Nine defined non-overlapping regions of interest (ROI, each $61.220 \mu \mathrm{m}^{2}$, $3 \mathrm{ROI}$ in the cortex, $3 \mathrm{ROI}$ in the hippocampus and $3 \mathrm{ROI}$ in the thalamus) were visualized by fluorescence microscopy $(40 \times$ objective; Axioplan; Zeiss, Germany) connected to a CCD camera (Axiocam ICc1, Zeiss). Mean values for each region and animal were calculated. Since neuronal density is not modulated in the contralateral hemisphere in our model [5], values of the ipsilateral hemisphere were related to contralateral values. Single cell counting was not possible in the contralateral hemisphere due to dense neuronal cell density in the neuronal layer. Therefore, $\mathrm{NeuN}^{+}$areas were quantified and \% neuronal loss was calculated according to the following equation: $100-((\mathrm{NeuN}$ area ipsilateral*100)/NeuN area contralateral)). For quantification of TUNEL $^{+}$cells, unbiased software based object detection (Image J, NIH, USA) was used to determine the number of degenerating cells in the ipsilateral hemisphere. Confocal imaging (A1plus, Eclipse Ti, with NIS Elements AR software, Nikon, Germany) was used for assessment of microglia activation and polarization in Iba- 1 and CD86/ CD206 stained tissue sections. Using the $20 \times$ objective $\mathrm{z}$-stack images of $10 \mu \mathrm{m}$ thickness $(1 \mu \mathrm{m}$ focal plane distance) were acquired in 7 ROIs (each: $99.729 \mu \mathrm{m}^{2}$, 3 ROI in the hippocampus, $2 \mathrm{ROI}$ in the thalamus, $2 \mathrm{ROI}$ in the cortex). Images were converted into maximal intensity projections for quantification. CD86 single, CD206 single and CD86/CD206 double positive cells were counted. Single object counting was not possible for Iba-1 staining due to intensive local accumulation of microglia in severely injured regions and animals. Therefore, positively stained areas were quantified as a measure of cell density and activation.

\section{Processing of brain tissues for flow cytometry and magnetic activated cell sorting (MACS)}

1,3 and 7 days after $\mathrm{HI}$, animals were deeply anesthetized by i.p. injections of an overdose chloralhydrate followed by transcardial perfusion with ice-cold PBS and removal of brains. Two hemispheres were pooled per sample to get a sufficient amount of $C D 11 b^{+}$cells after MACS. Brain tissues were mechanically and enzymatically dissociated using the Neural tissue dissociation kit followed by myelin removal according to the manufacturer's instructions (Miltenyi Biotech, Germany). The cell suspension was incubated with anti-CD11b coupled magnetic microbeads followed by magnetic separation of $C D 11 b^{+}$cells. A small aliquot of sorted cells $\left(1-2 \times 10^{5}\right)$ was used for flow cytometry to determine purity, cellular composition and polarization. The remaining cells were centrifuged, and cell pellets were frozen at $-80{ }^{\circ} \mathrm{C}$ until further processing. For comparison of the impact of different tissue homogenization and cell isolation procedures on the composition of isolated cells, brain hemispheres were dissected and homogenized through a $70 \mu \mathrm{m}$ cell strainer (BD Biosciences) by continuous rinsing with $15 \mathrm{~mL}$ of cold HEPES-buffered RPMI1640. Brain samples were centrifuged at $400 \mathrm{xg}$ for $10 \mathrm{~min}$ at $18{ }^{\circ} \mathrm{C}$. The supernatants were discarded and the pellets were resuspended in $15 \mathrm{~mL}$ of $37 \%$ Percoll in $0.01 \mathrm{~N} \mathrm{HCl} / \mathrm{PBS}$ and centrifuged at $2800 x g$ for $20 \mathrm{~min}$. Myelin was removed and the remaining cell pellet was washed twice in PBS followed by flow cytometry.

\section{Flow cytometry}

Isolated cells were incubated with anti-CD45 Alexa Fluor700 (1:200, clone: 30-F11, BD Biosciences), antiCD11b PE-Cy7 (1:800, clone M1/70, eBioscience), anti-Ly6G FITC (1:100, clone 1A8, BD Biosciences), anti-CD86 PE (1:400, clone GL-1, BD Biosciences), antiCD206 Brilliant Violett (1:50, clone C068C2, Biolegend) for $30 \mathrm{~min}$ at $4{ }^{\circ} \mathrm{C}$. Dead cells were excluded by staining with $1 \mu \mathrm{g} / \mathrm{ml}$ propidiumiodide (PI) prior to measurement. Brain resident brain microglia were identified as $\mathrm{CD} 11 \mathrm{~b}^{+} \mathrm{CD} 45^{\text {intermediate }}$ and infiltrated peripheral myeloid leukocytes as $\mathrm{CD} 11 \mathrm{~b}^{+} \mathrm{CD} 45^{\text {high }}$, which were further differentiated into neutrophils $\left(\mathrm{Ly}_{6} \mathrm{G}^{+}\right)$and macrophages $\left(\mathrm{Ly} 6 \mathrm{G}^{-}\right)$. Gates were set according to isolated cells prior to CD11b sorting. Myeloid cell polarization was evaluated by quantification of CD86 and CD206 single and double positive cells in the identified macrophage and microglia population. Gates were set according to fluorescence minus one (FMO) controls.

\section{mRNA expression analysis}

For mRNA expression analyses in sorted $C D 11 b^{+}$cells, total RNA was isolated with the RNeasy Micro Kit (Qiagen Germany) according to the manufactures recommendations. First strand complementary DNA was synthesized using $0.6 \mu \mathrm{g}$ of total RNA and TaqMan reverse transcription reagents (Applied Biosystems/ Thermo Fisher Scientific). Polymerase chain reaction (PCR) was performed in duplicates in 96 well optical reaction plates for 40 cycles with each cycle at $94{ }^{\circ} \mathrm{C}$ for $15 \mathrm{~s}$ and $60^{\circ} \mathrm{C}$ for $1 \mathrm{~min}$ using the StepOnePlus Real Time PCR system (Applied Biosystems/Thermo Fisher Scientific). PCR products were quantified using assay on demand primers and fluorogenic reporter oligonucleotide probes (Applied Biosystems/Thermo Fisher Scientific, Additional file 1: Table S1). CT values were normalized to the housekeeping gene beta-2-microglobulin $[\Delta C \mathrm{C}=\mathrm{CT}$ (target gene)-CT (beta-2-microglobulin)] and related to the mean of sham-operated animals 
using the $\Delta \Delta \mathrm{CT}$ formula $[\Delta \Delta \mathrm{CT}=\Delta \mathrm{CT}$ (sham) $-\Delta \mathrm{CT}$ $(\mathrm{HI}+\mathrm{NT} / \mathrm{HT})]$. Fold change values were calculated.

\section{Statistical analysis}

Results are expressed as box plots with individual data points including median values, the $25 \%$ and the $75 \%$ percentile or as bar graphs with mean \pm standard deviation. For statistical analysis, the GraphPad Prism 6.0 software package (GraphPad Software) was used. Data were analyzed by Two-way ANOVA with one factor timepoint (d1, d3, d7) or brain region (cortex, hippocampus, thalamus) and the other factor treatment (sham, HI $+\mathrm{NT}$, $\mathrm{HI}+\mathrm{HT}$ ). Whenever significant main or interaction effects were observed, post hoc analysis with Tukey's multiple comparison test regardless of means of factor 1 and factor 2 was applied. In all analyses, $p<0.05$ was considered statistically significant. Correlation analyses between the number of apoptotic cells/neuronal loss and Iba-1 immunoreactivity was performed with Pearsons' or Spearmann' correlation analyses depending on Gaussian distribution. For graphical presentation, individual data points and regression curves are shown.

\section{Results}

Neuroprotective effects of hypothermia develop over time To assess the impact of immediate HT on HI-induced brain injury, brain tissue sections were analyzed for neuropathological alterations and tissue atrophy in cresyl violet stained tissue sections (Fig. 1a). In spite of a slightly reduced neuropathology in HT-treated animals 3 days after $\mathrm{HI}$, most pronounced and significant protective effects were observed 7 days after injury, resulting from a gradual decrease in HT-treated animals between 1 and 7 days following HI (Fig. 1b). Furthermore, while NT animals revealed a gradual increase in HI-induced tissue loss between 1 and 7 days after HI, tissue loss was constant from day 3 onwards in HT-treated animals resulting a significantly reduced brain atrophy 7 days after $\mathrm{HI}$ (Fig. 1c).

To verify these results at the cellular level, we determined the number of degenerating cells and neuronal loss in different brain regions via immunohistochemistry for TUNEL and NeuN, respectively (Fig. 2). The most pronounced cellular degeneration was observed in the hippocampus, independent of treatment (Fig. 2a). Besides slightly reduced numbers of degenerating cells in the cortex and hippocampus in HT-treated animals at 1 and 3 days after $\mathrm{HI}$, no significant differences were detected between NT and HT groups (Fig. 2a). In line with analyses of cellular degeneration, the hippocampus revealed the highest degree of neuronal loss 3 and 7 days after HI (Fig. 2b). In spite of a slight decrease by HT treatment in the cortex and thalamus 3 days after HI, no significant differences were observed at this timepoint (Fig. 2b). However, we detected a significantly reduced neuronal loss in the hippocampus of HT-treated animals 7 days after HI, which resulted from a gradual increase in neuronal loss between 3 and 7 days in NT control animals (Fig. 2b).

\section{Hypothermia alters expression of typical M1 and M2 marker proteins in a time and region-specific manner} First, we evaluated the impact of HT on overall microglia activation by immunohistochemistry for Iba-1 (Fig. 3).

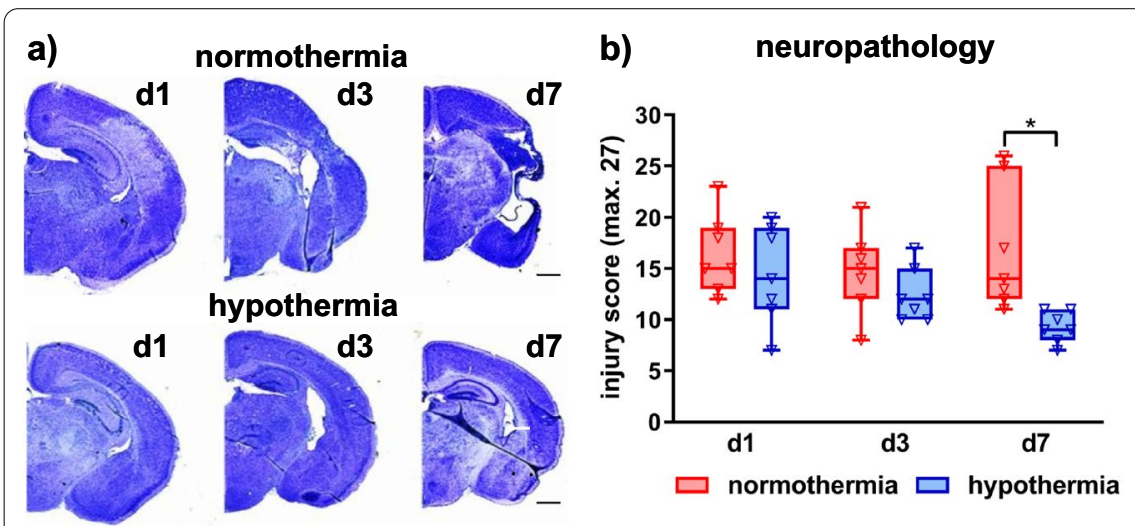

C) tissue atrophy

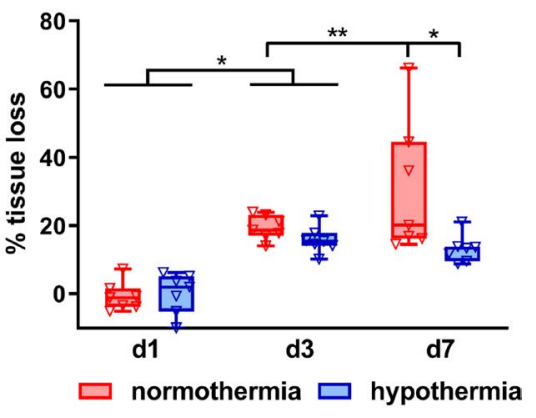

Fig. 1 Neuroprotection by hypothermia develops over time. Histological brain injury was determined in cresyl violet stained tissue sections 1, 3 and 7 days after $\mathrm{HI}$, performed in 9-day-old C57Bl/6 mice. Animals were exposed to $4 \mathrm{~h}$ hypothermia immediately after $\mathrm{HI}$. Controls were kept at physiological body core temperature (normothermia). Representative images of injured hemispheres for each experimental group are shown in $\mathbf{a}$, scale bar: $1 \mathrm{~mm}$. Injury scores were assessed in different brain regions (cortex, hippocampus, thalamus and striatum) resulting in a sum score, which was quantified for each animal (b). Brain atrophy was analyzed by measurement of intact tissue volumes at a distance of $400 \mu \mathrm{m}$ between $+1 \mathrm{~mm}$ and $-2.6 \mathrm{~mm}$ from bregma and volumes were calculated for total hemispheres (c). Tissue loss is expressed as the percentage of volume reduction compared to intact contralateral volumes (c). ${ }^{*} p<0.05,{ }^{*} p<0.01, n=7 /$ treatment and timepoint 

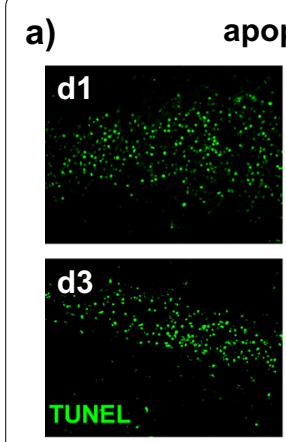

normothermia apoptosis
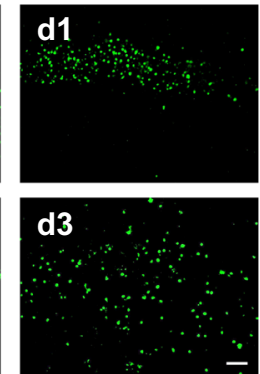

hypothermia

b) neuronal loss
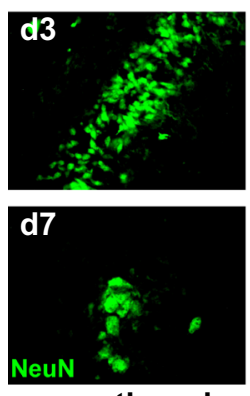

normothermia
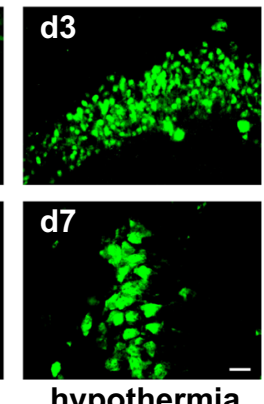

hypothermia

day 1

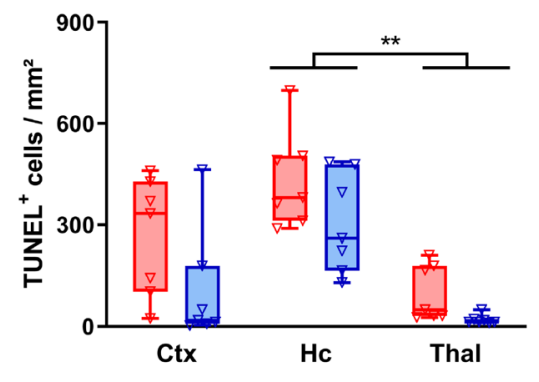

$\square$ normothermia $\square$ hypothermia day 3

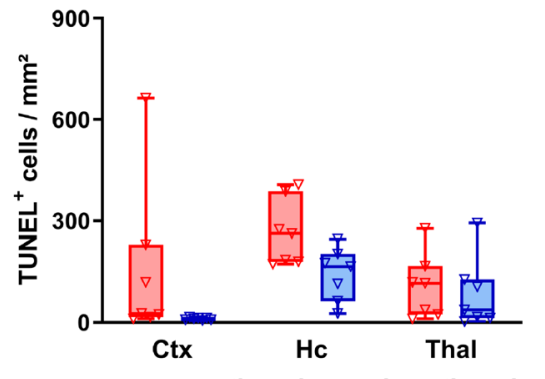

$\square$ normothermia $\square$ hypothermia

Fig. 2 Hypothermia protects from delayed neuronal cell death. Nine-day-old C57BL/6 mice were exposed to HI followed by $4 \mathrm{~h}$ hypothermia or normothermia. Animals were sacrificed and analyzed via immunohistochemistry 1, 3 or 7 days after HI. Cellular degeneration (a) and neuronal loss (b) were assessed by quanfication of TUNEL ${ }^{+}$cells and $\mathrm{NeuN}^{+}$areas, respectively, in the cortex (Ctx), hippocampus (Hc) and thalamus (Thal). Representative images in a are derived from the CA1 (NeuN) and CA2 (TUNEL) regions of the hippocampus, scale bar: $20 \mu \mathrm{m} .{ }^{* *} p<0.01,{ }^{* * *} p<0.001$. $n=7 /$ treatment and timepoint

a)

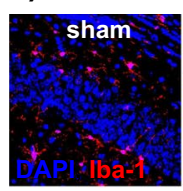

day 1
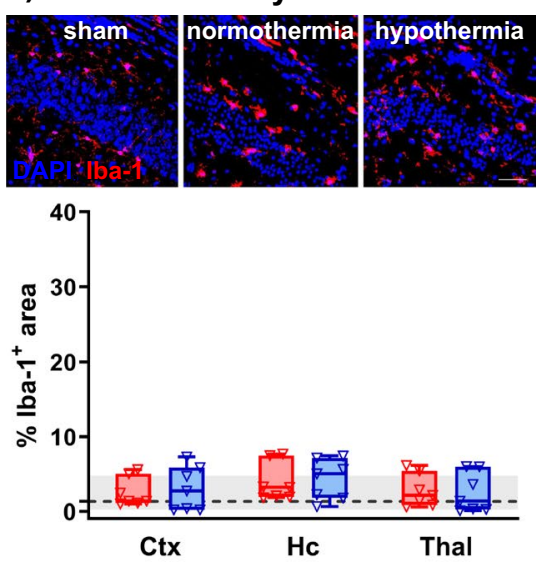

$\square$ normothermia $\square$ hypothermia b)

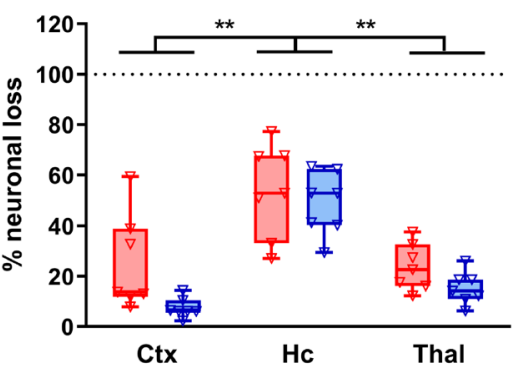

normothermia $\square$ hypothermia day 7

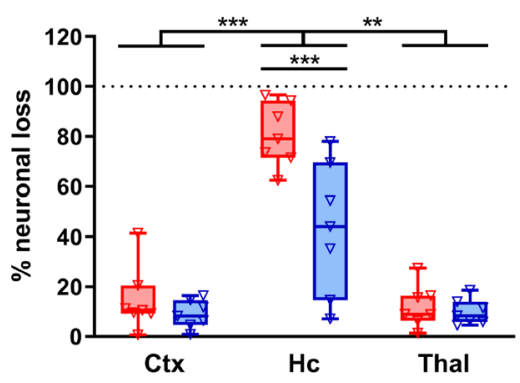

$\square$ normothermia $\square$ hypothermia c)
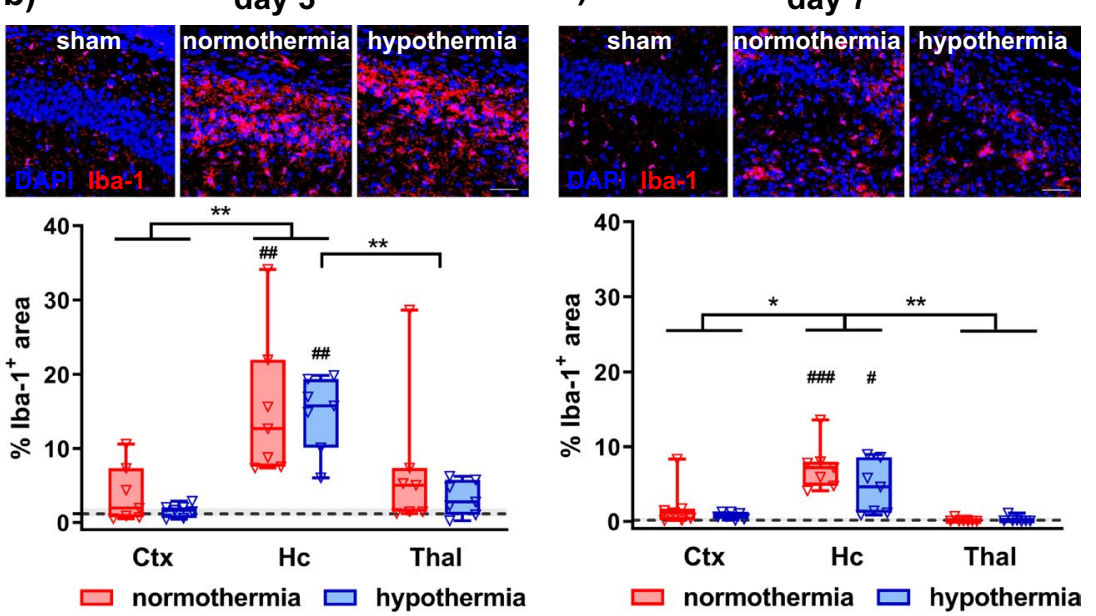

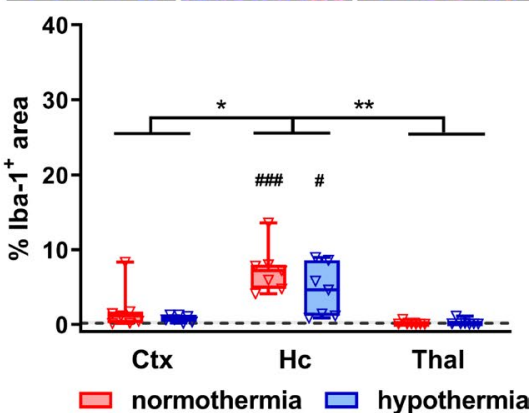

Fig. 3 Microglia activation peaks 3 days after $\mathrm{HI}$, but is not modulated by HT. Microglia activation was analyzed via immunohistochemistry for Iba-1 on day 1 (a), 3 (b) and 7 (c) after HI, performed in 9-day-old C57BL/6 mice. Animals were exposed to 4 h hypothermia immediately after HI. Controls were kept at physiological body core temperature (normothermia). Iba-1 immunoreactivity was quantified by measurement of positively stained areas in the cortex (Ctx), hippocampus ( $\mathrm{Hc}$ ) and thalamus (Thal). Representative images were acquired in the CA2 region of the hippocampus, scale bar: $50 \mu \mathrm{m}$. Dashed lines and grey shadows in the graphs indicate quantiles (i.e., median and $25^{\text {th }}, 75^{\text {th }}$ percentiles) of sham-operated animals across all timepoints, statistical comparisons to sham groups were performed for animals of the same timepoint. Detailed time course analyses of sham-operated animals are provided in the Additional file 1: Fig. S1. ${ }^{*} p<0.05,{ }^{* *} p<0.01,{ }^{\#} p<0.05,{ }^{\# \#} p<0.01,{ }^{\# \# \#} p<0.001$ vs. sham. $n=5$ (sham)/ timepoint, $n=7(\mathrm{HI}) /$ treatment and timepoint 
Iba-1 immunoreactivity did not differ compared to sham animals 1 day after injury (Fig. 3a). However, time course analyses demonstrated that microglia activation peaks 3 days after HI (Fig. 3a-c). In accordance with observed regional differences in HI-induced brain injury (Fig. 2), Iba-1 immunoreactivity was highest in the hippocampus, revealing significant differences between $\mathrm{HI}$-injured and sham control animals 3 and 7 days after $\mathrm{HI}$, which was, however, independent of treatment (Fig. 3b, c). No differences were observed in sham-operated animals between different timepoints and regions (Additional file 1: Fig. S1). To get deeper insight, whether HI-induced neuronal damage and microglia activation are interrelated or two independent events, we performed correlation analyses between the number of $\mathrm{TUNEL}^{+}$cells/\%neuronal loss with Iba-1 immunoreactivity (Additional file 1: Fig. S2a). Analyses over both treatment groups and all analyzed brain regions demonstrated a significant positive correlation 3 and 7 days but not 1 day after HI (Additional file 1: Fig. S2a). Separate correlation analyses for NT and HT groups further revealed a more pronounced correlation in HT-treated animals compared to NT 3 days after HI (Additional file 1: Fig. S2b).

To characterize myeloid cells in HI-injured brains more specifically, we assessed expression of two typical marker proteins, associated with classical M1 and alternative M2 activation, i.e., CD86 and CD206, respectively (Fig. 4). As previously described [12], in addition to single positive cells, we also detected a considerable amount of CD86 and CD206 double positive cells (Fig. 4a), even though the number of CD86 single positive cells was highest in all brain regions analyzed (Fig. 4b, Additional file 1: Fig. S3). In the hippocampus, the most severely injured brain region (Fig. 2), we observed an increase of CD86 positive cells between 3 and 7 days after HI in NT-treated animals, resulting in a significant difference compared to sham-operated control mice (Fig. 4b). In contrast, HT-treated animals revealed a decline in the number of $\mathrm{CD}^{+} 6^{+}$cells, which did not differ compared to healthy sham mice 7 days after injury (Fig. 4b). Furthermore, the amount of CD206 single positive cells rapidly increased between 1 and 3 days after HI in NT and HT animals, with more pronounced effects in HT-treated mice, leading to a significant difference compared to sham control animals 3 and 7 days after HI (Fig. 4c). Elevated numbers of CD86/CD206 double positive cells were detected 1 and 3 days after injury in NT- and HT-treated animals, respectively, while no additional differences were determined between timepoints and treatments (Fig. 4d). The number of CD86 and CD206 single and double positive cells was similar across all timepoints in sham-operated animals (Additional file 1: Fig. S4a).

Of note, the temporal expression of CD86 single positive cells in the hippocampus differed from that in the cortex and thalamus (Additional file 1: Fig. S3). While similar numbers were determined in NT- and HT-treated animals in the hippocampus, HT significantly reduced the number of $\mathrm{CD} 86^{+}$cells in the thalamus 1 day after

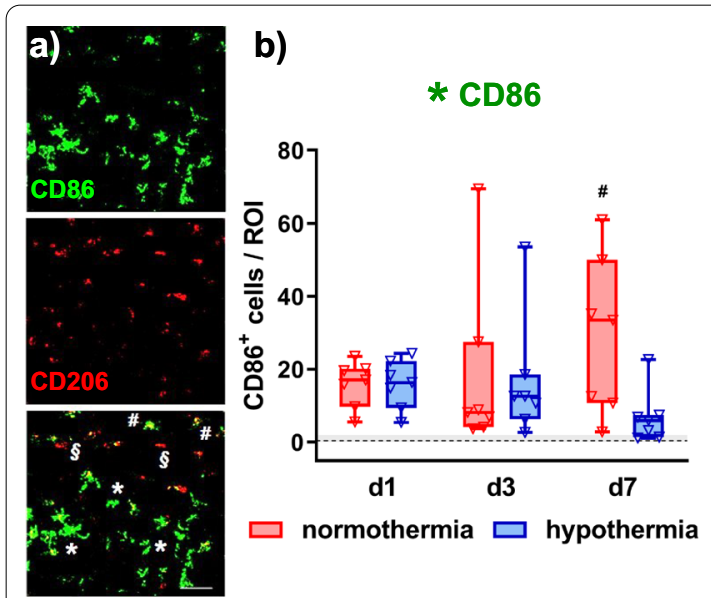

c)

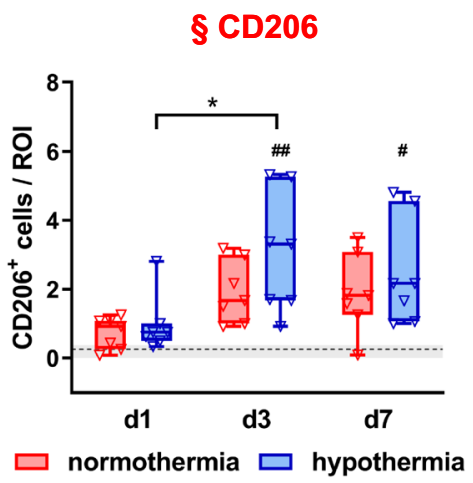

d)

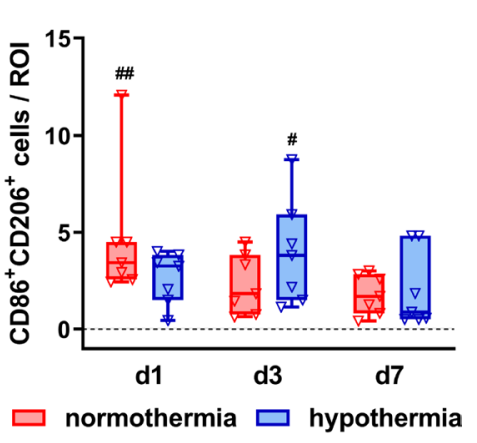

Fig. 4 Hypothermia alters temporal expression of typical M1 and M2 marker proteins in the hippocampus. Nine-day-old C57BL/6 mice were exposed to $\mathrm{HI}$ followed by $4 \mathrm{~h}$ hypothermia or normothermia. Animals were sacrificed and analyzed via immunohistochemistry 1,3 or 7 days after HI. Myeloid cell polarization was assessed via immunohistochemistry for the prototypical M1 marker CD86 (green) and the M2 marker CD206 (red) in the hippocampus (a, representative images are derived from the CA2 region of the hippocampus from an NT-treated animal 3 days after HI. Asterisks, paragraph symbols and rhombi indicate CD86 single, CD206 single and CD86/CD206 double positive cells, respectively; scale bar: $50 \mu \mathrm{m})$. CD86 single (b), CD206 single (c) and CD86/CD206 double (d) positive cells were quantified. Dashed lines and grey shadows in the graphs indicate quantiles (i.e., median and 25th, 75th percentiles) of sham-operated animals across all timepoints, statistical comparisons to sham groups were performed for animals of the same timepoint. Detailed time course analyses of sham-operated animals are provided in the Additional file 1: Fig. S4a. ${ }^{*} p<0.05 ;,{ }^{\#} p<0.05,{ }^{\#} p<0.01$ vs. sham. $n=5$ (sham)/timepoint, $n=7$ (HI)/treatment and timepoint 
HI (Fig. 4b, Additional file 1: Fig. S3a). Nevertheless, similar to the hippocampus, CD206 single positive cells increased with time in HT-treated animals leading to significantly elevated numbers 7 days after injury in the thalamus (Additional file 1: Fig. S3a). Due to high interindividual variability in the cortex, no differences were observed for CD86 and CD206 single positive cells in this region (Additional file 1: Fig. S3b). However, similarly as in the hippocampus and thalamus a significantly increased amount of CD86/CD206 double positive cells was detected in NT-treated animals 1 day after injury, which also significantly declined until 7 days after $\mathrm{HI}$ comparable to the thalamus (Additional file 1: Fig. S3). Compared to 3 days, a slightly increased number of CD86/CD206 double positive cells was detected in the thalamus of sham-operated animals 1 day after surgery (Additional file 1: Fig. S4b), which was, however, significantly smaller compared to HI-injured animals (Additional file 1: Fig. S3a). No significant time-dependent differences were observed for CD86 and CD206 expression in the cortex of sham animals (Additional file 1: Fig. S4c).

\section{Hypothermia decreases neonatal HI-induced infiltration of peripheral myeloid cells}

Since immunohistochemistry is limited to certain brain areas in a small part of the brain, we isolated myeloid cells from the total hemisphere via MACS of CD11b cells to assess expression of a broad set of genes associated with classical M1 and alternative M2 activation as well as immunomodulatory genes. Cell sorting efficiency was evaluated via flow cytometry, revealing a mean purity of $87.2 \pm 8.7 \%$, which did not differ between all groups analyzed (Fig. 5a, b). However, further detailed analyses of the composition of sorted cells according to their CD45 expression, enabling differentiation between brain resident microglia $\left(\mathrm{CD} 45^{\text {int }}\right)$ and myeloid cells derived from the periphery $\left(C D 45^{\text {high }}\right)$, revealed differences between sham and HI-injured animals but also between NT and HT-treatment (Fig. 5c, d). Surprisingly, we hardly detected neutrophils in sorted $C D 11 b^{+}$cells. However, comparison of standard isolation procedures for flow cytometry (Additional file 1: Fig. S5a) with cell isolation for MACS according to the manufacturer's instruction (Additional file 1: Fig. S5b) revealed that the isolation and tissue homogenization procedure for MACS depletes almost all neutrophils (Additional file 1: Fig. S5b,c). While the majority of sorted cells in sham

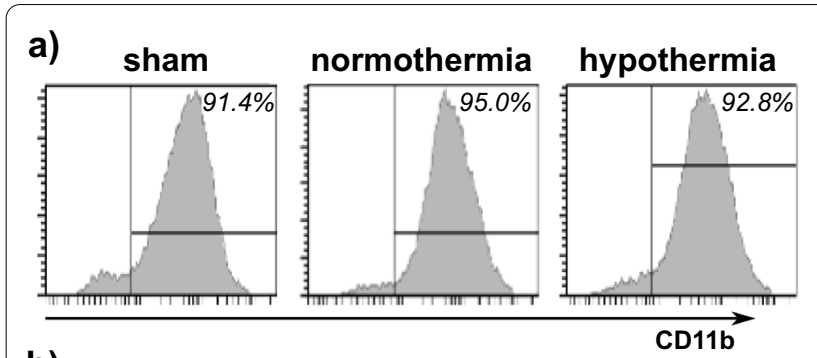

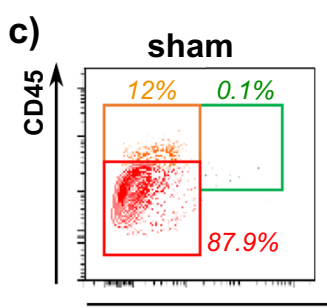
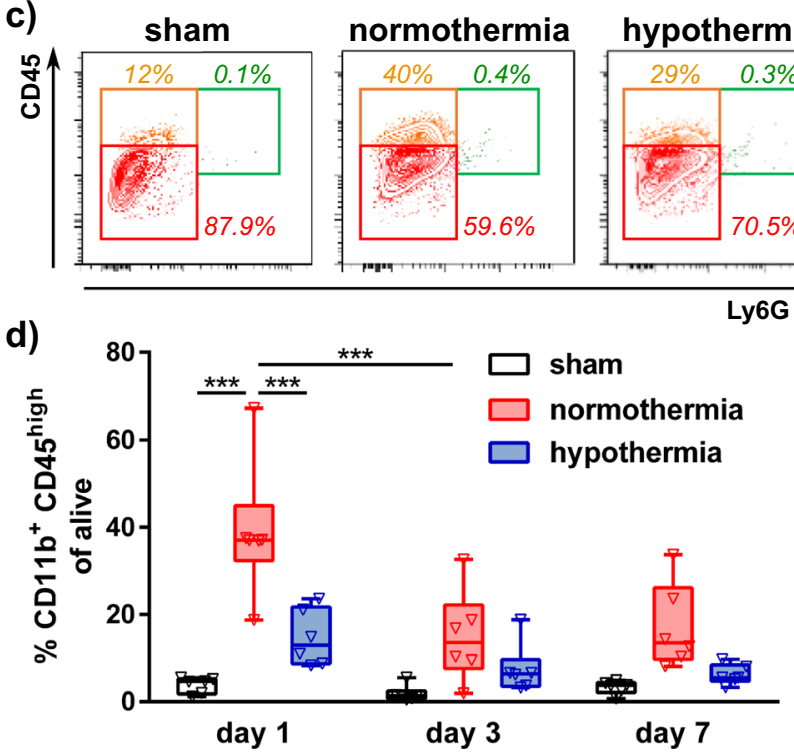

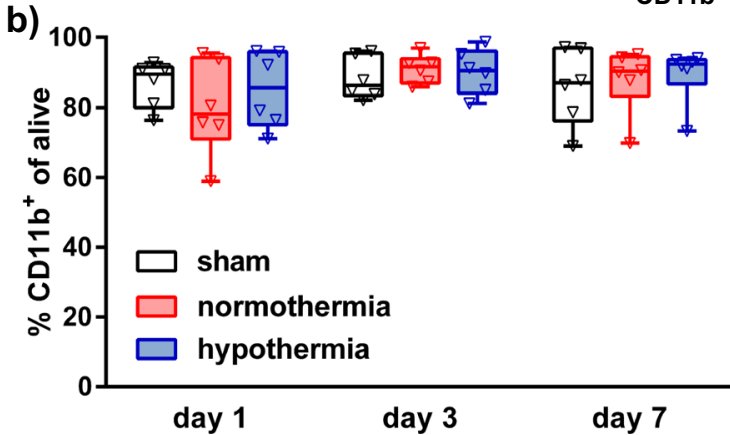

Fig. 5 Neonatal $\mathrm{HI}$ and $\mathrm{HT}$ modulate composition of ex vivo sorted $\mathrm{CD} 11 \mathrm{~b}^{+}$cells. 1, 3 and 7 days after $\mathrm{HI}$ or sham operation, $\mathrm{CD} 11 \mathrm{~b}^{+}$cells were isolated via MACS from brains of uninjured sham-operated and HI-injured animals exposed to immediate HT or NT. Flow cytometry with a small aliquot of isolated cells was used to determine purity isolated cells $(\mathbf{a}, \mathbf{b})$ and to characterize the composition of sorted myeloid cells $(\mathbf{c}, \mathbf{d})$. Purity of $C D 11 b^{+}$cells was quantified as the percentage of living, i.e., propdidumiodide (PI) negative cells (a, b). According to Ly6G and CD45 expression, sorted cells were distinguished in resident microglia (red gate: $\mathrm{CD} 11 \mathrm{~b}^{+} \mathrm{CD}_{4} 5^{\mathrm{int}} \mathrm{Ly} 6 \mathrm{G}^{-}$), peripheral monocytes/macrophages (orange gate: $\mathrm{CD}_{11} \mathrm{~b}^{+}$ $\mathrm{CD}_{4} 5^{\text {high }} \mathrm{Ly}_{6 \mathrm{G}^{-}}$) and neutrophils (green gate: $\mathrm{CD} 11 \mathrm{~b}^{+} \mathrm{CD} 45^{\text {high }} \mathrm{Ly} 6 \mathrm{G}^{+}$) in living (i.e., PI negative) cells (c, d). Gates were set according to samples obtained prior to MACS. ${ }^{* *} p<0.001, n=6$ animals/timepoint for sham (left and right hemisphere pooled), $n=12$ animals/timepoint for HI + NT and for $\mathrm{HI}+\mathrm{HT}$ ( 2 ipsilateral hemispheres pooled per sample). Histograms and contour plots in $\mathbf{a}$ and (b) are representative for cells isolated 1 day after HI 
animals were identified as resident microglia, a considerable amount of peripheral infiltrated macrophages was detected in sorted cells of HI-injured animals (Fig. 5c, d, Additional file 1: Fig. S5c). Importantly, the pronounced increase of peripheral macrophages in NT-treated HIinjured animals was significantly reduced by HT 1 day after HI (Fig. 5d). Furthermore, this early increase in macrophages rapidly declined 3 days after injury in both groups (Fig. 5d).

\section{Hypothermia differentially modulates CD86 and CD206 expression in myeloid cells of the total hemisphere}

To correlate our findings derived from region-specific immunohistochemistry for CD86 and CD206 expression, we further quantified the amount of single and double positive cells in ex vivo sorted $\mathrm{CD}_{11 \mathrm{~b}^{+}}$cells differentiating between microglia and peripheral macrophages (Fig. 6a). Similar to results obtained via immunohistochemistry, the amount of CD86 single positive cells was higher compared to CD206 single and double positive cells at all timepoints (Fig. 6). Comparable to observations in the hippocampus, the increase in CD206 single positive cells 3 days after $\mathrm{HI}$ was also detected in sorted myeloid cells of the total brain (Fig. 6b). Furthermore, an acute increase of CD86/CD206 double positive cells was determined in HI-injured animals compared to healthy sham controls, which was independent of treatment (Fig. 6c). Confirming observations in the hippocampus at day 1, CD86 single positive cells were increased in HI-injured animals compared to sham controls independent of treatment, while HT-treated animals had reduced numbers of CD86 positive cells 7 days after HI compared to NT-treated mice (Fig. 6d).

In contrast to immunohistochemistry, flow cytometry analyses enabled the differentiation between effects on resident microglia and macrophages derived from the periphery. On the one hand, both cell types partly revealed similar regulations, e.g., a significant increase of CD86/CD206 double positive cells in HI-injured animals 1 day after HI, independent of treatment (Fig. 6c, Additional file 1: Table S2). On the other hand, the acute increase in $\mathrm{CD}^{+} 6^{+}$cells in the total $\mathrm{CD} 11 \mathrm{~b}^{+}$cell

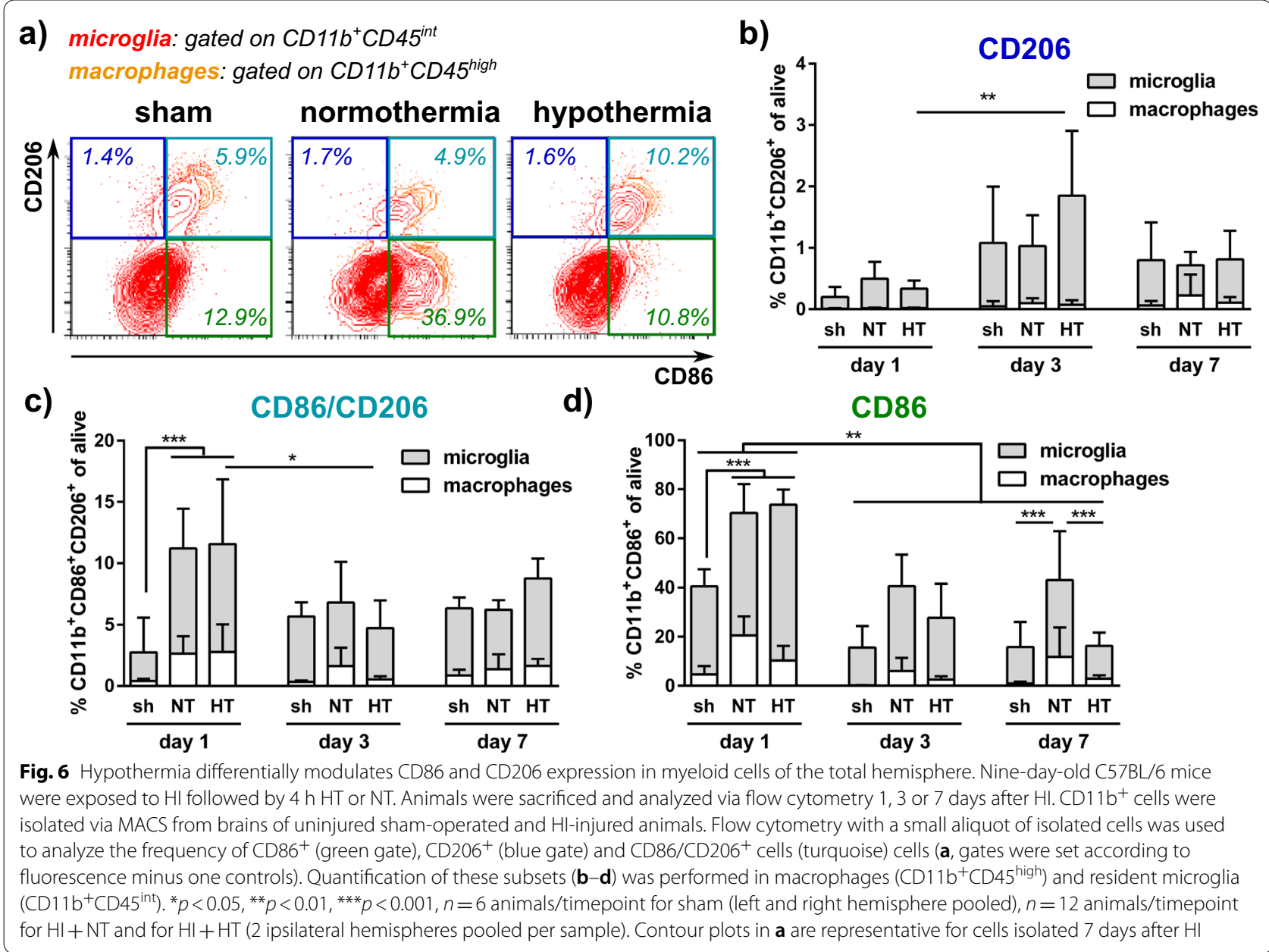


population of NT-treated HI-injured mice was mainly based on a significant increase in peripheral macrophages, which was reduced in HT-treated animals (Fig. 6d, Additional file 1: Table S2). Of note, the overall increase in CD206 single positive cells particularly in HTtreated animals was mainly due to an increase of these cells in the microglia population, while these cells were hardly detectable in peripheral macrophages (Fig. 6b, Additional file 1: Table S2).

\section{Hypothermia decreases $\mathrm{HI}$-induced upregulation of a broad set of inflammatory genes associated with classical $\mathrm{M} 1$ and alternative $\mathrm{M} 2$ activation}

To investigate a larger set of molecules associated with different myeloid cell polarization states, we performed gene expression analyses on MACS-sorted $\mathrm{CD}_{11} \mathrm{~b}^{+}$cells. Genes were assigned to M1 (iNOS, Cox2, CXCL-1, CCL2, IL-6, IL-18, TNF-alpha, IL-23, IL-1beta), immunomodulatory markers (Gal-3, SOCS3) and M2 (YM-1, Arg-1, Fizz-1, IL-10, TGF-beta) according to previous reports $[10-12,14,16,19]$. Interestingly, compared to sham animals, all analyzed genes were immediately upregulated after HI, which was, however, independent of myeloid cell classification (Additional file 1: Table S3). As such, the most upregulated genes compared to uninjured shamoperated animals were the immunomodulatory marker Gal-3 (mean fold change: 91.6), the M2 marker $Y M-1$ (mean fold change 58.5) and the M1 marker $I L-23$ (fold change: 29.1) (Additional file 1: Table S3, Fig. 7). Furthermore, for the majority of genes we detected a significantly increased expression in NT-treated HI-injured animals compared to HT-treated mice 1 day after HI, independent of myeloid cell classification (i.e., iNOS, Cox2, CCL-2, IL-6, IL-18, IL-23, Gal-3, YM-1, Fizz-1, TGF-beta, Fig. 7). This acute and partially strong increase rapidly declined 3 days after $\mathrm{HI}$ to levels of sham animals or even below (Fig. 7). However, we also identified a few exceptions, e.g., $I L-1$ beta and $I L-23$ revealed a delayed and a secondary increase, respectively, in NT-treated animals 7 days after HI, which was significantly reduced by HT (Fig. 7). Furthermore, Gal-3 displayed a sustained increase in NTtreated animals until 3 days after HI, which was significantly decreased by HT and which declined to the level of HT-treated animals 7 days after injury and intervention (Fig. 7).

\section{Discussion}

Therapeutic hypothermia (HT) is the standard therapy for the treatment of neonatal encephalopathy of presumed hypoxia-ischemia (HI). However, $30 \%$ of cooled infants still suffer from major neurological problems [3], because of a short therapeutic window (first $6 \mathrm{~h}$ of life) and a limited efficacy in more severe cases [4]. In spite of a large body of pre-clinical studies suggesting adjuvant therapies, clinical translation failed until now. Therefore, a better knowledge of hypothermia's effector mechanisms is needed to guide the rational design of combination treatments. Myeloid cells play a key role in HI pathophysiology, revealing a high phenotypic plasticity either participating in progression or resolution of injury-induced inflammation. In the present study, we demonstrate that HT-induced neuroprotection develops over time, which is preceded by a strong and acute suppression of $\mathrm{HI}$-induced upregulation of a large number of inflammatory genes in myeloid cells, associated with, both, classical M1 and alternative M2 activation. Furthermore, HT selectively inhibited secondary increases of pro-inflammatory cytokines and decreased HI-induced infiltration of peripheral myeloid cells.

Despite of a large number of studies including our own, demonstrating significant neuroprotection at delayed timepoints, i.e., 7-8 days after neonatal HI [5, 9, 23-26], reports on HT effects on early cellular degeneration are still contradicting. On the one hand, reduced apoptosis (i.e., caspase- 3 and TUNEL) was observed $6 \mathrm{~h}$ after $\mathrm{HI}$ in a piglet and in a rat model $[27,28]$. On the other hand, several reports could not demonstrate significant protection from acute cell death in severely affected brain regions, i.e., the hippocampus. For instance, HT was significantly neuroprotective in the caudate nucleus but not in the hippocampus in a severe neonatal HI piglet model $48 \mathrm{~h}$ after HI [29]. These data are in line with our previous report in neonatal rats, where we also did not detect significant protection by HT from acute cellular degeneration $48 \mathrm{~h}$ after HI [30]. Furthermore, no obvious differences were observed for the number of apoptotic cells between NT and HT-treated animals 1 day after

(See figure on next page.)

Fig. 7 Hypothermia suppresses HI-induced upregulation of a large number of inflammatory genes in myeloid cells. To investigate a large set of genes associated with different myeloid cell polarization states, mRNA expression analyses was performed via real time PCR on MACS-sorted $\mathrm{CD} 11 \mathrm{~b}^{+}$cells from brains of $\mathrm{C} 57 \mathrm{BI} / 6$ mice exposed to $\mathrm{HI}$ at P9 followed by immediate HT or NT. Uninjured sham-operated animals served as controls. A broad set of typical M1 (red heading), immunoregulatory (orange heading) and M2 (green heading) marker genes were analyzed. Beta-2-microglobulin served as housekeeping gene and fold change values compared to sham-operated control animals were calculated. ${ }^{*} p<0.05$, ${ }^{* *} p<0.01,{ }^{* * *} p<0.001, n=6$ animals/timepoint for sham (left and right hemisphere pooled), $n=12$ animals/timepoint for HI + NT and for HI + HT ( 2 ipsilateral hemispheres pooled per sample) 

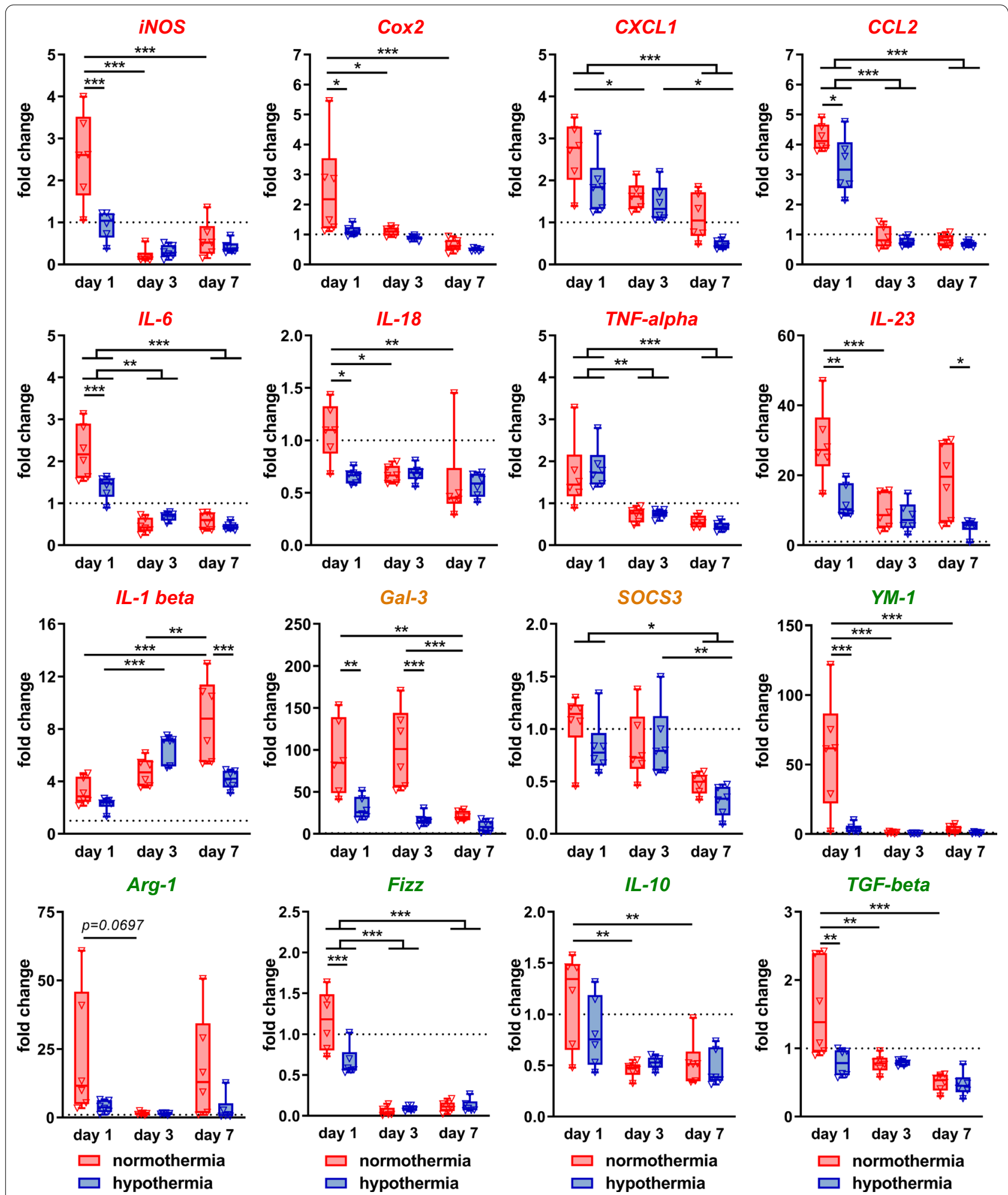

Fig. 7 (See legend on previous page.) 
HI in 7-day-old rats [31]. In support of this, in the present study we also did not observe significant differences in the number of TUNEL-positive cells 1 day after HI. However, 3 days after $\mathrm{HI}$ a slight, though not significant, reduction of cellular degeneration was detected in the hippocampus, which resulted in a significantly decreased neuronal loss 7 days after HI. Together, these data indicate that neuroprotective effects of HT develop over time and become most obvious at the subacute disease phase.

According to previous clinical and pre-clinical reports suggesting that HT is more efficient in moderate than in severe injury cases $[26,32]$, we used our previously established model in 9-day-old C57BL/6 mice. This model produces moderate to severe hippocampal brain injury, which can be significantly attenuated by the HT protocol, applied in the present study [5, 9]. Therefore, our experimental paradigm is particularly suitable to investigate mechanisms underlying effector mechanisms of HT. In contrast to rats, it is hardly possible to produce more severe injury also in other brain regions (i.e., cortex and thalamus) by, e.g., increasing temperature or hypoxia severity due to an inacceptable high mortality of $50 \%$ in C57BL/6 mice in these severe injury models $[5,22]$. Though mild injury in the cortex and thalamus may provide first insights into therapeutic efficacy of HT in mild HIE, valid conclusions would need larger sample sizes due to small effect sizes of the HI insult in these regions. Previous preclinical reports in rats, however, already provide first indications that HT may also protect from mild HI-induced brain injury [33], which is also increasingly discussed in the clinical setting [34, 35]. In addition to the severity of the HI insult, the present HT protocol may be important for interpretation of results. While clinical studies and large animal models suggested that $72 \mathrm{~h} \mathrm{HT}$ provides best therapeutic effects $[3,32,36]$, a consensus about the optimal cooling protocol in neonatal rodents, particularly in mice, is still missing. However, the vast majority of rodent studies applied short HT (4-5 h), all of them showing neuroprotection, though with different effect sizes [5, 9, 23, 24, 37, 38]. Considering pronounced differences in physiology between rodents and large animals/humans, longer durations may not necessarily increase neuroprotective effects. This is supported by the few studies, applying longer HT durations in rodents, which did not show an additional benefit of longer cooling $[26,39-41]$. Nevertheless, these rodent studies also emphasize the utmost importance of large animal models for translational research, which was not the main purpose of the present study. The major aim was the identification of cellular and molecular mechanisms, underlying neuroprotective effects of HT.

Our time course analyses of inflammatory processes specifically focusing on myeloid cells, i.e., microglia and infiltrated myeloid cells from the periphery, demonstrate a distinct temporal and spatial pattern of cell activation and phenotypic plasticity. In line with limited neuroprotection 3 days after injury, Iba- 1 immunoreactivity was not modulated by HT. These data are supported by correlation analyses, which demonstrated a significant positive correlation between apoptosis/neuronal loss and Iba-1 immunoreactivity in HT-treated animals 3 days after HI. Though our experimental paradigm discussed above may provide an explanation for limited effects of HT on Iba-1 reactivity, it should also be taken into account that HT may only delay HI-induced neurodegenerative processes [42] and possibly associated inflammatory responses. Our results of Iba-1 immunoreactivity rather argue against this hypothesis, because, both, NT and HT-treated animals showed the same peak in the first week. Nevertheless, the continuous increase of CD86 and IL-1beta expression until 7 days, observed in NTtreated animals, may indicate ongoing secondary and tertiary inflammatory mechanisms [43], which might be delayed by HT. Therefore, future studies should include later timepoints of analyses. In spite of a strong correlation between neuronal loss and Iba-1 in both treatment groups 7 days after HI, neuroprotective effects of HT were not accompanied by differences in Iba- 1 immunoreactivity at this timepoint. These results indicate that other mechanisms also contribute to HT-induced neuroprotection in the sub-acute disease phase. Furthermore, in view of the enormous heterogeneity of this cell population, sole Iba-1 immunoreactivity might not be suitable for conclusions about microglia/myeloid cell phenotype and function. This is supported by our gene expression analyses in sorted $\mathrm{CD}_{11 \mathrm{~b}^{+}}$cells and by several reports demonstrating that myeloid cell populations differ in morphology and inflammatory profile, not only depending on the time course of disease but also on brain regions [44-46].

Regional differences also need to be considered for interpretation of our results derived from flow cytometry and immunohistochemistry for the M1 marker CD86 and the M2 marker CD206. For instance, while a second increase in CD86 single positive cells between 3 and 7 days was specifically detected in the hippocampus, a gradual decrease was observed in the myeloid cell population obtained from the total hemisphere. These findings support that microglia/macrophages responses to the HI insult but also to HT may differ between different brain regions. Nevertheless, both, immunohistochemistry and flow cytometry revealed that $\mathrm{HI}$ induces an acute increase in CD86 single and CD86/CD206 double positive myeloid cells. HT significantly reduced the amount of $\mathrm{CD} 86^{+}$cells 7 days after $\mathrm{HI}$ and increased the number of CD206 ${ }^{+}$cells 3 days after HI. Even though these 
data indicate that HT modulates myeloid cell polarization from a pro-inflammatory M1 phenotype to an antiinflammatory M2 phenotype, the detection of double positive cells is in line with previous reports and highlights that this strict M1/M2 classification concept might oversimplify the complexity of myeloid cell responses in vivo [12]. Another crucial aspect, which needs to be considered, but was not in the primary scope of the present study, is the impact of sex. Though not powered enough, preliminary exploratory sex-stratified analyses of the present immunohistochemistry results revealed an increased neuroprotective effect of HT in the hippocampus of females (Additional file 1: Fig. S6a-c), supporting previous reports [38]. With regard to inflammatory responses, an overall increased number of $\mathrm{CD}^{+} 6^{+}$cells was detected in males 3 days after HI (Additional file 1: Fig. S6e), which is in line with previous work in a model of neonatal ischemic stroke, demonstrating an increased pro-inflammatory profile in myeloid cells, isolated from male mice [17]. In support of this, it was recently shown that depletion of myeloid cells provides neuroprotection in males but not in females [47]. Females revealed larger numbers of CD86/CD206 double positive cells, particularly in HT-treated animals (Additional file 1: Fig. S6g). However, clear-cut conclusions about potential sexdifferences in myeloid cell responses to HI and HT will require further studies with larger sample sizes to combat the well-known model-associated variability.

While neuroprotective effects of HT became particularly evident at later timepoints, our myeloid cell specific gene expression analyses uncovered early and very distinct molecular regulations in myeloid cells in response to HI and HT. Almost all analyzed genes including typical M1, M2 and immunoregulatory markers were strongly upregulated in NT-treated HI-injured animals 1 day after the insult. Compared to previous studies on total tissue lysates, temporal regulations detected in the present work seem to differ. For example, Hellström-Erkenstam et al. observed the most pronounced upregulation for the majority of genes already $6 \mathrm{~h}$ after HI, which rapidly decreased within $24 \mathrm{~h}$, resulting in no differences between contra- and ipsilateral hemispheres for most of the genes [12]. Furthermore, even though our previous mRNA expression analyses in total tissue lysates also showed reductions below sham levels for, e.g., Cox-2 and iNos, other genes (e.g., IL-6 and TNF-alpha) were upregulated 7 days after HI [13], which is in contrast to the present results obtained from sorted myeloid cells. These discrepancies demonstrate the advantage of cell-specific analysis performed in the present study and suggest that other CNS cell types also contribute to the inflammatory response following neonatal HI. Nevertheless, the elegant possibility of selective analysis of ex vivo sorted myeloid cells is limited to draw conclusions, whether regulations were caused by peripheral monocytes/macrophages or resident microglia. Indeed, our cell-type-specific flow cytometry analyses for CD86 and CD206 revealed that the acute increase in $\mathrm{CD}^{+} 6^{+}$cells in NT treated HIinjured mice in the total CD11b cell population was mainly based on a significantly increased expression in peripheral macrophages. Furthermore, the overall increase of CD206 single positive cells, particularly in HT-treated animals, was mainly due to an increase of these cells in the microglia population, while these cells were hardly detectable in peripheral macrophages. Differential immune cell composition and different effects on different cell populations most likely also explain the observed decline below sham levels for several genes 3 and 7 days after HI. Finally, the observed reduced infiltration of peripheral macrophages in HT-treated animals 1 day after HI, may partly explain HT-induced downregulation of the majority of inflammatory genes at this early timepoint.

In addition to the acute effects of $\mathrm{HT}$ on a broad variety of inflammatory genes, our gene expression screening uncovered potentially important effector molecules mediating HT-induced neuroprotection on delayed neuronal death after neonatal HI. The late increase in IL-1beta and IL-23 indicates that HI induces selective long-lasting inflammatory alterations in myeloid cells, which is supported by previous studies demonstrating a gradual and sustained increase of IL-1beta from 1 to 14 days after HI $[48,49]$. Furthermore, the secondary increase in IL-23 seems to be an important mechanism considering the pro-inflammatory role of this cytokine in several inflammatory diseases [50] and cerebral ischemia, where IL-23p19 knockdown prevented delayed cerebral ischemic injury by dampening ischemia-induced inflammation [51]. Considering that HT suppressed these delayed inflammatory responses, our present findings suggest that myeloid cell derived IL-1beta and IL-23 play an important role in subacute evolvement of HI-induced brain injury, which can be attenuated by acute HT.

In view of our own and other studies, either demonstrating interaction or non-additive effects of adjuvant therapies [6-9], the present study results provide potential mechanistic insights. We have previously shown that mesenchymal stem cells (MSC) given 3 days after $\mathrm{HI}$ and HT are less efficient compared to MSC given to NT-treated mice. As a potential mechanism we identified modulation of MSCs with an increased pro-inflammatory and reduced regenerative profile due to the altered brain environment after HT. Interestingly, while we did not detect any differences between NT and HT in myeloid cells for the majority of genes 3 days after, Gal-3 was the only molecule, revealing a sustained and robust 
expression (fold change $>100$ ) 3 days after HI, which was strongly downregulated by HT. The role of the immunomodulatory molecule Gal-3 in ischemic brain injury is still controversially discussed, either providing neuroprotection in adult brain injury or promoting neurodegeneration in neonatal $\mathrm{HI}$-induced brain injury $[52,53]$. This is further complicated by the fact that Gal-3 is expressed in resident microglia but also peripheral monocytes/macrophages. Nevertheless, Gal-3 is supposed to be important for immunomodulatory functions of MSCs $[54,55]$. Considering our previous results of MSC-modulation by the brain environment 3 days after $\mathrm{HI}$ and $\mathrm{HT}$, a reasonable hypothesis for future studies might be that myeloid cell-secreted Gal-3 is needed for immunosuppressive function of MSCs and/or to enhance MSCs' own Gal-3 expression in vivo. Therefore, either later timepoints of stem cell therapy, i.e., 7 days after $\mathrm{HI}$, when Gal-3 expression is at similar levels in both, NT and HT conditions, or additional therapies to promote Gal-3 expression after HT might present new approaches to improve outcome of stem cell therapy in the obligate clinical setting of HT.

\section{Conclusions}

In the present study, we demonstrate that HT-induced neuroprotection develops over time. Neuroprotective effects are preceded by a strong and acute suppression of HI-induced upregulation of a large number of inflammatory genes in myeloid cells, associated with both, classical M1 and alternative M2 activation. These findings support the overall criticism on the previously suggested strict M1/M2 classification based on single molecule expression. In addition, we demonstrate that HT significantly decreases $\mathrm{HI}$-induced infiltration of peripheral myeloid cells and suppresses the secondary increase of specific pro-inflammatory genes. Our study highlights the importance of time course analyses and the need to consider the complex interplay between peripheral and CNS-resident immune cells. Future studies should perform selective analyses on specific cell types differentiating between resident microglia and different peripheral leukocyte subsets to identify specific targets for therapeutic intervention. Nevertheless, the pronounced early and delayed immunomodulatory effects represent important shortand long-term effector mechanisms of HT, which most likely combine to promote neuroprotection. We identified selective target molecules and potential new therapeutic windows that may pave the way for the rational design of adjuvant therapies.

\section{Abbreviations}

Arg1: Arginase 1; CCL2: Chemokine (C-C motif) ligand 2; Cox2: Cyclooxygenase-2; CXCL1: Chemokine (C-X-C motif) ligand 1; Fizz1: Resistin-like alpha;
Gal-3: Lectin, galactose binding, soluble 3; HI: Hypoxia-ischemia; HT: Hypothermia; IL-10: Interleukin-10; IL-18: Interleukin-18; IL-1 beta: Interleukin-1 beta; IL-23: Interleukin 23, alpha subunit p19; IL-6: Interleukin-6; iNos: Nitric oxide synthase 2; NT: normothermia; MACS: Magnetic activated cell sorting; SOCS3: Suppressor of cytokine signaling 3; TGF beta: Transforming growth factor beta1; TNF alpha: Tumor necrosis factor alpha; YM1: Chitinase-like protein 3.

\section{Supplementary Information}

The online version contains supplementary material available at https://doi. org/10.1186/s12974-021-02314-9.

Additional file 1. Additional figures and tables.

\section{Acknowledgements}

We thank K. Kempe and M. Rizazad for excellent technical assistance, J. Göthert and M. Möllmann for the opportunity to perform flow cytometry analysis with BD FACS LSRII and R. Herrmann for fruitful discussions of gene expression analyses.

\section{Authors' contributions}

$\mathrm{JH}$ and IB conceptualized the study and designed the project. MSei, CK, MSer, $\mathrm{JH}$ and IB performed experiments and analyzed data. UF provided financial support. MD, HS and UF provided critical comments and suggestions during the drafting of the manuscript. JH and IB wrote the manuscript. All authors read and approved the final manuscript.

\section{Funding}

Open Access funding enabled and organized by Projekt DEAL. This work was supported by the C.D.-Stiftung, the Karl-Heinz-Frenzen Foundation and the Else-Kröner-Fresenius-Stiftung (ELAN).

\section{Availability of data and materials}

All data generated or analyzed during this study are included in this published article and its supplementary information files.

\section{Declarations}

Ethics approval and consent to participate

Animal experiments were performed with government approval by the State Agency for Nature, Environment and Consumer Protection North RhineWestphalia. C57BL/6J mice were initially ordered from Charles River bred in house afterwards.

\section{Consent for publication}

Not applicable.

\section{Competing interests}

The authors declare that they have no competing interests.

\section{Author details}

${ }^{1}$ Department of Pediatrics I, Neonatology \& Experimental Perinatal Neurosciences, University Hospital Essen, University Duisburg-Essen, Hufelandstr. 55, 45147 Essen, Germany. ${ }^{2}$ Center for Translational Neuro-and Behavioral Sciences (C-TNBS), University Hospital Essen, University Duisburg-Essen, Essen, Germany. ${ }^{3}$ Department of Neonatology and Pediatric Intensive Care, Children's Hospital, University of Bonn, Bonn, Germany. ${ }^{4}$ German Centre for Neurodegenerative Diseases, Bonn, Germany.

Received: 20 July 2021 Accepted: 1 November 2021

Published online: 13 November 2021

\section{References}

1. Ahearne CE, Boylan GB, Murray DM. Short and long term prognosis in perinatal asphyxia: an update. World J Clin Pediatr. 2016;5:67-74. 
2. Thornberg E, Thiringer K, Odeback A, Milsom I. Birth asphyxia: incidence, clinical course and outcome in a Swedish population. Acta Paediatr. 1995;84:927-32.

3. Shankaran S, Laptook AR, Pappas A, McDonald SA, Das A, Tyson JE, Poindexter BB, Schibler K, Bell EF, Heyne RJ, et al. Effect of depth and duration of cooling on death or disability at age 18 months among neonates with hypoxic-ischemic encephalopathy: a randomized clinical trial. JAMA. 2017;318:57-67.

4. Jacobs SE, Berg M, Hunt R, Tarnow-Mordi WO, Inder TE, Davis PG. Cooling for newborns with hypoxic ischaemic encephalopathy. Cochrane Database Syst Rev. 2013;1:CD003311.

5. Reinboth BS, Koster C, Abberger H, Prager S, Bendix I, Felderhoff-Muser $U$, Herz J. Endogenous hypothermic response to hypoxia reduces brain injury: Implications for modeling hypoxic-ischemic encephalopathy and therapeutic hypothermia in neonatal mice. Exp Neurol. 2016;283:264-75.

6. Azzopardi D, Robertson NJ, Bainbridge A, Cady E, Charles-Edwards G, Deierl A, Fagiolo G, Franks NP, Griffiths J, Hajnal J, et al. Moderate hypothermia within $6 \mathrm{~h}$ of birth plus inhaled xenon versus moderate hypothermia alone after birth asphyxia (TOBY-Xe): a proof-of-concept, open-label, randomised controlled trial. Lancet Neurol. 2016;15:145-53.

7. George S, Bennet L, Weaver-Mikaere L, Fraser M, Bouwmans J, Mathai S, Skinner SJ, Gunn AJ. White matter protection with insulin-like growth factor 1 and hypothermia is not additive after severe reversible cerebral ischemia in term fetal sheep. Dev Neurosci. 2011;33:280-7.

8. George SA, Barrett RD, Bennet L, Mathai S, Jensen EC, Gunn AJ. Nonadditive neuroprotection with early glutamate receptor blockade and delayed hypothermia after asphyxia in preterm fetal sheep. Stroke. 2012:43:3114-7.

9. Herz J, Koster C, Reinboth BS, Dzietko M, Hansen W, Sabir H, van Velthoven C, Bendix I, Felderhoff-Muser U. Interaction between hypothermia and delayed mesenchymal stem cell therapy in neonatal hypoxicischemic brain injury. Brain Behav Immun. 2018;70:118-30.

10. Hu X, Leak RK, Shi Y, Suenaga J, Gao Y, Zheng P, Chen J. Microglial and macrophage polarization-new prospects for brain repair. Nat Rev Neurol. 2015:11:56-64.

11. Chhor V, Le Charpentier T, Lebon S, Ore MV, Celador IL, Josserand J, Degos V, Jacotot E, Hagberg H, Savman K, et al. Characterization of phenotype markers and neuronotoxic potential of polarised primary microglia in vitro. Brain Behav Immun. 2013;32:70-85.

12. Hellstrom Erkenstam N, Smith PL, Fleiss B, Nair S, Svedin P, Wang W, Bostrom M, Gressens P, Hagberg H, Brown KL, et al. Temporal characterization of microglia/macrophage phenotypes in a mouse model of neonatal hypoxic-ischemic brain injury. Front Cell Neurosci. 2016;10:286.

13. Kaminski N, Koster C, Mouloud Y, Borger V, Felderhoff-Muser U, Bendix I, Giebel B, Herz J. Mesenchymal stromal cell-derived extracellular vesicles reduce neuroinflammation, promote neural cell proliferation and improve oligodendrocyte maturation in neonatal hypoxic-ischemic brain injury. Front Cell Neurosci. 2020;14:601176.

14. Chhor V, Moretti R, Le Charpentier T, Sigaut S, Lebon S, Schwendimann L, Ore MV, Zuiani C, Milan V, Josserand J, et al. Role of microglia in a mouse model of paediatric traumatic brain injury. Brain Behav Immun. 2017;63:197-209.

15. Serdar M, Kempe K, Rizazad M, Herz J, Bendix I, Felderhoff-Muser U, Sabir $\mathrm{H}$. Early pro-inflammatory microglia activation after inflammation-sensitized hypoxic-ischemic brain injury in neonatal rats. Front Cell Neurosci. 2019;13:237.

16. Van Steenwinckel J, Schang AL, Krishnan ML, Degos V, Delahaye-Duriez A, Bokobza C, Csaba Z, Verdonk F, Montane A, Sigaut S, et al. Decreased microglial Wnt/beta-catenin signalling drives microglial pro-inflammatory activation in the developing brain. Brain. 2019;142:3806-33.

17. Villapol S, Faivre V, Joshi P, Moretti R, Besson VC, Charriaut-Marlangue C: Early Sex Differences in the Immune-Inflammatory Responses to Neonatal Ischemic Stroke. Int J Mol Sci 2019, 20.

18. Davidson JO, Yuill CA, Zhang FG, Wassink G, Bennet L, Gunn AJ. Extending the duration of hypothermia does not further improve white matter protection after ischemia in term-equivalent fetal sheep. Sci Rep. 2016;6:25178

19. Lee JH, Wei ZZ, Cao W, Won S, Gu X, Winter M, Dix TA, Wei L, Yu SP. Regulation of therapeutic hypothermia on inflammatory cytokines, microglia polarization, migration and functional recovery after ischemic stroke in mice. Neurobiol Dis. 2016;96:248-60.
20. Herz J, Koster C, Crasmoller M, Abberger H, Hansen W, Felderhoff-Muser U, Bendix I. Peripheral T cell depletion by FTY720 exacerbates hypoxicischemic brain injury in neonatal mice. Front Immunol. 2018:9:1696.

21. Mulling K, Fischer AJ, Siakaeva E, Richter M, Bordbari S, Spyra I, Koster C, Hermann DM, Gunzer M, Felderhoff-Muser U, et al. Neutrophil dynamics, plasticity and function in acute neurodegeneration following neonatal hypoxia-ischemia. Brain Behav Immun. 2021;92:234-44.

22. Sheldon RA, Sedik C, Ferriero DM. Strain-related brain injury in neonatal mice subjected to hypoxia-ischemia. Brain Res. 1998;810:114-22.

23. Burnsed JC, Chavez-Valdez R, Hossain MS, Kesavan K, Martin LJ, Zhang $J$, Northington FJ. Hypoxia-ischemia and therapeutic hypothermia in the neonatal mouse brain - a longitudinal study. PLOS ONE. 2015;10:e0118889.

24. Carlsson Y, Wang X, Schwendimann L, Rousset Cl, Jacotot E, Gressens P, Thoresen M, Mallard C, Hagberg H. Combined effect of hypothermia and caspase-2 gene deficiency on neonatal hypoxic-ischemic brain injury. Pediatr Res. 2012;71:566-72.

25. Ma D, Hossain M, Chow A, Arshad M, Battson RM, Sanders RD, Mehmet $H$, Edwards AD, Franks NP, Maze M. Xenon and hypothermia combine to provide neuroprotection from neonatal asphyxia. Ann Neurol. 2005;58:182-93.

26. Sabir H, Scull-Brown E, Liu X, Thoresen M. Immediate hypothermia is not neuroprotective after severe hypoxia-ischemia and is deleterious when delayed by 12 hours in neonatal rats. Stroke. 2012;43:3364-70.

27. Lafuente H, Pazos MR, Alvarez A, Mohammed N, Santos M, Arizti M, Alvarez FJ, Martinez-Orgado JA. Effects of cannabidiol and hypothermia on short-term brain damage in new-born piglets after acute hypoxiaischemia. Front Neurosci. 2016;10:323.

28. Shah TA, Pallera HK, Kaszowski CL, Bass WT, Lattanzio FA. Therapeutic hypothermia inhibits the classical complement pathway in a rat model of neonatal hypoxic-ischemic encephalopathy. Front Neurosci. 2021;15:616734.

29. Kovacs V, Remzso G, Toth-Szuki V, Varga V, Nemeth J, Domoki F. Inhaled $\mathrm{H} 2$ or $\mathrm{CO} 2$ do not augment the neuroprotective effect of therapeutic hypothermia in a severe neonatal hypoxic-ischemic encephalopathy piglet model. Int J Mol Sci. 2020;21:1.

30. Klofers M, Kohaut J, Bendix I, Herz J, Boos V, Felderhoff-Muser U, Dzietko M. Effects of poly(ADP-ribose) polymerase-1 inhibition in a neonatal rodent model of hypoxic-ischemic injury. Biomed Res Int. 2017:2017:2924848

31. Xiong M, Chen LX, Ma SM, Yang Y, Zhou WH. Short-term effects of hypothermia on axonal injury, preoligodendrocyte accumulation and oligodendrocyte myelination after hypoxia-ischemia in the hippocampus of immature rat brain. Dev Neurosci. 2013;35:17-27.

32. Davies A, Wassink G, Bennet L, Gunn AJ, Davidson JO. Can we further optimize therapeutic hypothermia for hypoxic-ischemic encephalopathy? Neural Regen Res. 2019;14:1678-83.

33. Sabir H, Bonifacio SL, Gunn AJ, Thoresen M, Chalak LF, Newborn Brain Society G, Publications C: Unanswered questions regarding therapeutic hypothermia for neonates with neonatal encephalopathy. Semin Fetal Neonatal Med 2021:101257.

34. Chawla S, Bates SV, Shankaran S. Is it time for a randomized controlled trial of hypothermia for mild hypoxic-ischemic encephalopathy? J Pediatr. 2020;220:241-4.

35. El-Dib M, Inder TE, Chalak LF, Massaro AN, Thoresen M, Gunn AJ. Should therapeutic hypothermia be offered to babies with mild neonatal encephalopathy in the first $6 \mathrm{~h}$ after birth? Pediatr Res. 2019:85:442-8.

36. Shankaran S, Laptook AR, Pappas A, McDonald SA, Das A, Tyson JE, Poindexter BB, Schibler K, Bell EF, Heyne RJ, et al. Effect of depth and duration of cooling on deaths in the NICU among neonates with hypoxic ischemic encephalopathy: a randomized clinical trial. JAMA. 2014;312:2629-39.

37. Patel SD, Pierce L, Ciardiello A, Hutton A, Paskewitz S, Aronowitz E, Voss $\mathrm{HU}$, Moore H, Vannucci SJ. Therapeutic hypothermia and hypoxiaischemia in the term-equivalent neonatal rat: characterization of a translational preclinical model. Pediatr Res. 2015;78:264-71.

38. Wood TR, Gundersen JK, Falck M, Maes E, Osredkar D, Loberg EM, Sabir $\mathrm{H}$, Walloe L, Thoresen M. Variability and sex-dependence of hypothermic neuroprotection in a rat model of neonatal hypoxic-ischaemic brain injury: a single laboratory meta-analysis. Sci Rep. 2020;10:10833. 
39. Ahn SY, Chang YS, Sung DK, Sung SI, Park WS. Hypothermia broadens the therapeutic time window of mesenchymal stem cell transplantation for severe neonatal hypoxic ischemic encephalopathy. Sci Rep. 2018;8:7665.

40. Lee BS, Woo CW, Kim ST, Kim KS. Long-term neuroprotective effect of postischemic hypothermia in a neonatal rat model of severe hypoxic ischemic encephalopathy: a comparative study on the duration and depth of hypothermia. Pediatr Res. 2010;68:303-8.

41. Park WS, Sung SI, Ahn SY, Yoo HS, Sung DK, Im GH, Choi SJ, Chang YS. Hypothermia augments neuroprotective activity of mesenchymal stem cells for neonatal hypoxic-ischemic encephalopathy. PLOS ONE. 2015;10:e0120893.

42. Trescher WH, Ishiwa S, Johnston MV. Brief post-hypoxic-ischemic hypothermia markedly delays neonatal brain injury. Brain Dev. 1997;19:326-38.

43. Fleiss B, Gressens P. Tertiary mechanisms of brain damage: a new hope for treatment of cerebral palsy? Lancet Neurol. 2012;11:556-66.

44. Fleiss B, Van Steenwinckel J, Bokobza C. Microglia-mediated neurodegeneration in perinatal brain injuries. Biomolecules. 2021;11:1.

45. Savchenko VL, McKanna JA, Nikonenko IR, Skibo GG. Microglia and astrocytes in the adult rat brain: comparative immunocytochemical analysis demonstrates the efficacy of lipocortin 1 immunoreactivity. Neuroscience. 2000;96:195-203.

46. Jacobs AJ, Castillo-Ruiz A, Cisternas CD, Forger NG. Microglial depletion causes region-specific changes to developmental neuronal cell death in the mouse brain. Dev Neurobiol. 2019;79:769-79.

47. Smith PLP, Mottahedin A, Svedin P, Mohn CJ, Hagberg H, Ek J, Mallard C. Peripheral myeloid cells contribute to brain injury in male neonatal mice. J Neuroinflamm. 2018;15:301.

48. Hedtjarn M, Leverin AL, Eriksson K, Blomgren $\mathrm{K}$, Mallard C, Hagberg $\mathrm{H}$. Interleukin-18 involvement in hypoxic-ischemic brain injury. J Neurosci. 2002;22:5910-9.
49. Sun Y, Calvert JW, Zhang JH. Neonatal hypoxia/ischemia is associated with decreased inflammatory mediators after erythropoietin administration. Stroke. 2005;36:1672-8.

50. Pastor-Fernandez G, Mariblanca IR, Navarro MN. Decoding IL-23 signaling cascade for new therapeutic opportunities. Cells. 2020;9:1.

51. Zheng Y, Zhong D, Chen H, Ma S, Sun Y, Wang M, Liu Q, Li G. Pivotal role of cerebral interleukin-23 during immunologic injury in delayed cerebral ischemia in mice. Neuroscience. 2015;290:321-31.

52. Doverhag C, Hedtjarn M, Poirier F, Mallard C, Hagberg H, Karlsson A, Savman K. Galectin-3 contributes to neonatal hypoxic-ischemic brain injury. Neurobiol Dis. 2010;38:36-46.

53. Wesley UV, Sutton IC, Cunningham K, Jaeger JW, Phan AQ, Hatcher JF, Dempsey RJ. Galectin-3 protects against ischemic stroke by promoting neuro-angiogenesis via apoptosis inhibition and Akt/Caspase regulation. J Cereb Blood Flow Metab. 2021;41:857-73.

54. Sioud M, Mobergslien A, Boudabous A, Floisand Y. Evidence for the involvement of galectin-3 in mesenchymal stem cell suppression of allogeneic T-cell proliferation. Scand J Immunol. 2010;71:267-74.

55. Souza BSF, da Silva KN, Silva DN, Rocha VPC, Paredes BD, Azevedo CM, Nonaka CK, Carvalho GB, Vasconcelos JF, Dos Santos RR, Soares MBP. Galectin-3 knockdown impairs survival, migration, and immunomodulatory actions of mesenchymal stromal cells in a mouse model of chagas disease cardiomyopathy. Stem Cells Int. 2017;2017:3282656.

\section{Publisher's Note}

Springer Nature remains neutral with regard to jurisdictional claims in published maps and institutional affiliations.
Ready to submit your research? Choose BMC and benefit from:

- fast, convenient online submission

- thorough peer review by experienced researchers in your field

- rapid publication on acceptance

- support for research data, including large and complex data types

- gold Open Access which fosters wider collaboration and increased citations

- maximum visibility for your research: over $100 \mathrm{M}$ website views per year

At BMC, research is always in progress.

Learn more biomedcentral.com/submissions 